\title{
Fatores protetores de adolescentes contra o uso de drogas com ênfase na religiosidade
}

\author{
Protective factors from adolescents against drug \\ use emphasizing the role of religiosity
}

Zila Van der Meer Sanchez 1

Lúcio Garcia de Oliveira 1

Solange Aparecida Nappo 2

\footnotetext{
1 Departamento de Psicobiologia da Universidade Federal de São Paulo (Unifesp). Rua Botucatu 862/10 andar, 04023-062, São Paulo SP. zila@psicobio.epm.br

2 Centro Brasileiro de Informações sobre Drogas Psicotrópicas (CEBRID/Unifesp). solange@psicobio.epm.br
}

Abstract Although a wide variety of studies have been emphasizing risk factors on drug use, it has not been given importance to protective factors' role, a fundamental key on development of prevention programs. As low socio-economic level are considered risk factors, the aim of this study was to investigate, among low purchasing power adolescents, factors that could prevent them against drug consumption. To reach this aim, qualitative methodology and a purposeful sample achieved by criteria were adopted. Sixty-two young people, users and non-users of drug, were submitted to interview. Amongst the protective factors, the familiar structure and religiosity were the most frequently reported by interviewees. Concerning on religious beliefs, it was observed the following results: $81 \%$ of the non-users believe and practices a religion; amongst users, only 13\% of them had the same behavior as non-users, assigning to the religion practice a way to leave drugs. It may be concluded that religion is a relevant protector factor for the studied sample, acting as familiar structure support and as an important source of information.

Key words Religiosity, Drugs, Prevention, Adolescents
Resumo Embora muitos estudos tenham retratado os fatores de risco ao uso de drogas, não tem sido dada a devida importância aos fatores de proteção, fundamentais para prevenção. Como o baixo nível socioeconômico é considerado fator de risco, o objetivo deste estudo foi identificar, entre adolescentes de baixo poder aquisitivo, quais seriam os fatores que pudessem preveni-los do consumo de drogas. Para essa investigação, adotou-se metodologia qualitativa e amostra intencional selecionada por critérios. Sessenta e dois jovens, usuários e não-usuários de drogas, foram submetidos à entrevista semi-estruturada. Entre os fatores protetores, a estrutura familiar e a religiosidade foram os mais freqüentemente citados. Quanto à religiosidade, foram observados os seguintes resultados: $81 \%$ dos não-usuários acreditam e praticam uma religião; entre os usuários, apenas $13 \%$ encontram-se nessa condição, atribuindo à prática religiosa um meio de abandono às drogas. Conclui-se que a religião pode ser um fator protetor relevante na amostra estudada, atuando como apoio na estruturação familiar e como importante fonte de informações.

Palavras-chave Religiosidade, Drogas, Prevenção, Adolescentes 


\section{Introdução}

Diversos estudos vêm enfatizando os fatores de risco e proteção relativos ao uso de drogas (Newcomb, 1995). No entanto, a maioria deles oferece subsídios para a compreensão dos fatores de risco, muitas vezes ignorando os fatores protetores (Scheier et al., 1994; Baus et al., 2002; Huesca et al., 2002; Pentz, 2003), que podem ser de grande valia na elaboração de programas de prevenção efetivos contra o uso de drogas (NIDA, 1997; De Micheli \& Formigoni, 2001; Hanson, 2002).

De acordo com levantamento realizado por Hanson (2002), os principais fatores protetores ao uso de drogas incluem: a família (pelo estabelecimento de laços afetivos entre seus membros; monitoramento das atividades e amizades do adolescente; construção de conduta social adequada); forte envolvimento com atividade escolar e/ou religiosa e disponibilidade de informações convencionais sobre o uso de drogas.

Segundo De Micheli \& Formigoni (2002), a baixa condição socioeconômica é um importante fator de risco ao uso de drogas, somado a isso, Carr \& Vandiver (2001) relatam ser a pobreza um grande estressor e fator de risco para que jovens se tornem delinqüentes.

O tráfico nas favelas e arredores acaba por gerar condições favoráveis ao uso de drogas, assim como maior oferta de consumo, implicando um ambiente permissivo ao uso de substâncias ilícitas (Newcomb, 1995). Outro fator de risco seria a própria adolescência, citada como o período de maiores chances para o inicio do consumo dessas substâncias (Dupont, 1987; Sanchez \& Nappo, 2002). Essa constatação coloca os adolescentes, pelo menos em tese, particularmente suscetíveis ao uso de drogas. Vários autores comungam dessa afirmação, quando identificam a faixa etária do início do uso de drogas dentro da adolescência, ou seja, entre 10 e 19 anos de acordo com a OMS (Kandel \& Logan, 1984; Piko, 2000; De Micheli \& Formigoni, 2001; Sanchez \& Nappo, 2002; Chaturvedi et al., 2003) sendo que, entre estudantes brasileiros, este início de consumo ocorreria principalmente entre 10 e 12 anos (Galduróz et al., 1998).

Embora esses estudos sejam relevantes para a melhor compreensão dos motivos que conduzem adolescentes ao uso de drogas psicotrópicas, pouco se sabe a respeito dos fatores protetores dentro de um grupo de risco, ou seja, razões que possam explicar o não-uso de drogas por adolescentes pertencentes a esses gru- pos (Scheier et al, 1994; Baus et al, 2002; De Micheli \& Formigoni, 2001).

Galduróz et al. (1997) em estudo conduzido em 10 capitais brasileiras, com a participação de mais de 15 mil estudantes de 10 e $2 \underline{o}$ graus, concluíram que $25 \%$ desses estudantes fizeram uso de alguma droga psicotrópica (além de álcool e tabaco) pelo menos uma vez na vida. Embora preocupante, o mesmo estudo revela também que $75 \%$ desses estudantes nunca fizeram uso de drogas na vida, despertando a curiosidade a respeito dos fatores responsáveis pela decisão do não-uso. O que permitiria a um adolescente, como parte de um grupo de risco, a decisão de não experimentar drogas?

Embora a importância da religiosidade fosse citada como elemento na recuperação e no tratamento de dependentes de substâncias psicotrópicas (Carter, 1998; Pullen et al., 1999; Arnold et al., 2002), é cada vez maior o número de trabalhos que a apontam como importante fator de prevenção ao consumo inicial de drogas por adolescentes (Francis, 1997; Miller, 1998; Patock-Peckham, 1998; Miller et al., 2000; De Micheli \& Formigoni, 2001). Ainda de acordo com esses autores, a avaliação da religiosidade é geralmente realizada por parâmetros que envolvem o comparecimento a uma "igreja”, prática religiosa e crença em Deus ou nos preceitos da religião professada. Assim, foi proposta uma associação inversa entre a religiosidade do adolescente e o uso inicial de substâncias psicotrópicas, ou seja, quanto mais religioso o adolescente menor seria seu interesse pelo consumo (Miller, 1998; Blum et al., 2003; Wills et al., 2003).

$\mathrm{O}$ presente estudo investigou os fatores protetores, contra o consumo de drogas, segundo a ótica de jovens pertencentes a uma população de risco, averiguando quais fatores, entre eles a religiosidade, seriam importantes como forma de prevenção. Foi realizada uma investigação profunda que esclarecesse certas dúvidas, tais como: Quais seriam os fatores que adolescentes de baixo padrão socioeconômico, usuários e não-usuários, julgariam como fundamentais na proteção contra o uso de drogas? Será que a religião, de alguma maneira, poderia auxiliar como forma de prevenção? Existiria a crença e prática da religiosidade no quotidiano desses sujeitos?

O esclarecimento dessas dúvidas partiu de duas situações antagônicas do problema, ou seja, do sucesso alcançado por alguns quando 
da tentativa de não usar drogas e do insucesso de outros.

\section{Metodologia}

Utilizou-se metodologia qualitativa, que permitiu investigar em profundidade questões relativas ao comportamento diante do uso de drogas por adolescentes e jovens adultos moradores de favelas, conjuntos habitacionais do governo e casebres aos arredores (Creswell, 1998).

A escassez de estudos brasileiros a respeito da existência de fatores protetores ao uso de drogas para adolescentes morando em um ambiente de risco, como o tráfico nas favelas, levou-nos à escolha de uma metodologia qualitativa que permitiu investigar com grande profundidade esse fenômeno (Patton, 1990; Taylor \& Bogdan, 1998).

Amostra: Em estudos qualitativos são utilizadas amostras intencionais, ou seja, fazem parte da amostra os casos ricos em informações sobre o tema. Neste estudo, a amostra intencional utilizada foi a amostragem com critérios, isto é, foram selecionados indivíduos ricos em informações e que ainda estivessem dentro de alguns critérios previamente definidos, de importância para o entendimento do assunto (Patton, 1990; Taylor \& Bogdan, 1998).

A amostragem qualitativa não privilegia o critério numérico, mas sim a capacidade de refletir a totalidade do fenômeno nas suas múltiplas dimensões. Os componentes da amostra são os sujeitos sociais que detêm os atributos que o investigador pretende conhecer (Minayo, 1993). Embora esses sujeitos possibilitem um melhor entendimento de um fenômeno pouco conhecido, os dados encontrados no estudo não podem ser generalizados a outras populações diferentes da estudada.

Fatores de inclusão na amostra: Fizeram parte deste estudo adolescentes e jovens adultos entre 16 e 24 anos, de ambos os sexos, de classe social baixa que nunca usaram drogas psicotrópicas ou que fizeram uso abusivo destas drogas (define-se como abusivo, o consumo diário e descontrolado de drogas, gerador, em potencial, de danos morais, pessoais e sociais ao usuário). Os dois grupos foram, respectivamente, denominados de NU (não-usuários) e U (usuários).

Entre os não-usuários (NU) ficou estabelecido que não poderiam ter feito uso, na vida, de drogas ilícitas e nem sequer tê-las experimentado. Quanto ao uso de drogas lícitas, permitiu-se a participação de sujeitos que tivessem feito apenas uso experimental de cigarro (definido como inferior a 5 vezes na vida) e/ou uso leve de álcool (definido como esporádico e não-abusivo) (OMS in Galduróz et al. 1998).

A classe social baixa foi determinada, principalmente, a partir do local e tipo de moradia (favela e casebres aos arredores), considerando-se também o fato do entrevistado ter cursado ou estar cursando escolas públicas de ensino fundamental e médio. O tamanho da amostra foi o suficiente para garantir a inclusão de todos os perfis a serem analisados e que satisfizesse aos critérios estabelecidos. Para ambos os grupos o fato pode ser detectado quando os entrevistados chegaram à redundância, atingindo o ponto de saturação teórica, ou seja, as informações passaram a se repetir, nenhuma nova informação foi descoberta e os dados obtidos não contribuíam para compreensões adicionais (Patton, 1990; Minayo, 1993; WHO, 1994; Taylor \& Bogdan, 1998).

Entrevistas com informantes-chave (Key Informants), que são pessoas que possuem um conhecimento especial da população em estudo (WHO, 1994), foram o primeiro passo para a obtenção da amostra. Esses intermediários funcionaram no estudo não só como pessoas que facilitaram a aproximação dos investigadores com a população em estudo, como também forneceram subsídios para a elaboração do questionário aplicado a todo jovem investigado (Patton, 1990; Taylor \& Bogdan, 1998). Foram entrevistados como informantes-chave: 4 profissionais da saúde diretamente ligados ao trabalho na área de abuso de drogas e populações de risco; 3 religiosos (católico, protestante e espírita); 1 ex-traficante, usuária de drogas, moradora da favela; 1 moradora de favela, que nunca experimentou drogas.

Os investigados foram recrutados pela técnica em cadeias, ou bola-de-neve (Biernacki \& Waldorf, 1981), em que os primeiros entrevistados indicam outros, que por sua vez indicam outros, e assim sucessivamente. A seleção desses indivíduos, dentro de cada cadeia, respeitou os critérios de inclusão da amostra, o princípio da aleatoriedade e o voluntariado. Os entrevistados não pertenciam ao mesmo grupo religioso, ou seja, não foram realizadas entrevistas com sujeitos que freqüentassem a mesma igreja ou comunidade religiosa, caso fossem praticantes de alguma religião. Assim sendo, foi 
possível a obtenção de 12 cadeias de diferentes origens quanto ao local de moradia (bairro), escola e comunidade religiosa.

Instrumentos utilizados: Foi utilizada, como instrumento de investigação, entrevista semi-estruturada direcionada por questionário. Algumas das questões contidas no questionário foram previamente padronizadas, enquanto outras foram desenvolvidas ao longo da entrevista. Um conjunto de questões básicas foi formulado a todo entrevistado, de modo a permitir a comparabilidade de respostas, além de reduzir a interferência do entrevistador e facilitar a organização e análise dos dados (Patton, 1990; Creswell, 1998). Os tópicos centrais do questionário, de forma geral, visavam avaliar a percepção do entrevistado a respeito de cada um dos temas (Ex.: uso ou não de drogas), além de investigar sua vivência em todos os aspectos abordados. Com exceção dos dados sociodemográficos que buscaram o conhecimento da condição financeira, cultural e social do indivíduo, os outros tópicos tinham por objetivo a identificação e compreensão dos fatores de risco/proteção ao uso de drogas, tema central do trabalho.

As entrevistas semi-estruturadas foram totalmente anônimas e gravadas com a concordância prévia do entrevistado. Após concluídas, foram transcritas e passaram por todas as fases de análise. As entrevistas foram realizadas em pequenas salas dentro do Departamento de Psicobiologia da Unifesp, que caracterizadas pela neutralidade e segurança, garantiram a adequação do ambiente ao tipo de intervenção conduzida. Todos os entrevistados foram ressarcidos pelo tempo e gastos com locomoção até o local da entrevista.

Análise dos dados: As entrevistas foram identificadas com um código alfanumérico significando, pela ordem: inicial do nome do entrevistado, idade do entrevistado, inicial do sexo do entrevistado (F ou M) e U para usuário e NU no caso de não-usuário. Relatos dos entrevistados são transcritos no item Resultados e Discussão e são destacados em negrito e itálico, permitindo melhor compreensão dos dados.

Após a transcrição completa das entrevistas previamente gravadas, seguiu-se a análise destas por meio dos seguintes passos, resumidos: "leituras flutuantes" das entrevistas de modo a entrar em contato exaustivo com o material; "procedimentos exploratórios" empregados de forma a iniciar a formulação de possíveis hipóteses; “preparação do material”, com desmem- bramento das entrevistas e agrupamento de respostas de acordo com os tópicos e questões abordadas. Permitiu a categorização das informações, possibilitando a identificação do comportamento dos entrevistados diante do tema abordado. Finalmente, procedeu-se ao "tratamento dos resultados", os quais foram submetidos a operações simples como freqüências absolutas e relativas, destacando-se as informações obtidas. A partir desse ponto, inferências e interpretações, em relação ao tema investigado puderam ser estabelecidas. Além disso, as hipóteses, cuja formulação teve início na etapa de "procedimentos exploratórios", puderam ser refutadas ou aceitas nessa última fase do trabalho (Minayo, 1993).

\section{Resultados e discussão}

\section{Dados sociodemográficos}

Dos 62 entrevistados, 32 sujeitos nunca experimentaram nenhum tipo de droga psicotrópica ilícita na vida, enquanto que os 30 restantes fizeram uso abusivo dessas drogas. Os dados sociodemográficos dos grupos $\mathrm{NU}$ e $\mathrm{U}$ (respectivamente, não-usuários e usuários) são mostrados no quadro 1.

Em ambos os grupos observou-se a predominância de sujeitos solteiros que continuavam morando com a família. O local de moradia como parte dos Critérios de Inclusão na Amostra, embora não apresentado no quadro 1 , mostrou-se extremamente pobre e violento, com parcos recursos e sujeito às condições impostas pelo tráfico vigente, deixando clara a situação de vida às quais os entrevistados estavam expostos. Relatos como os mostrados a seguir enfatizam a classe social dos entrevistados e as condições do tráfico e violência na região:

Aí já era favela mesmo, a minha casa era assim, tinha uma casa na frente, a minha casa era no meio e passava um rio atrás, um rio que ligava as lagoa, aí quando enchia alagava tudo ali dentro. (B17MNU)

...é um quintal com bastante casa. São nove casas num quintal. Toda a família: desde vó, bisneto, tataraneto, tia, primo... São nove casas, tudo família. A casa é um quarto e cozinha. (B18FU)

...Às vezes você passa no corredor, você vê um monte de cara armado, polícia toda hora. Você sempre vê os caras lá jogado, os nóia... Se tá devendo, os caras vão lá buscar ele e os caras matam na porta da bocada e manda o outro carregar de 


\begin{tabular}{|c|c|c|}
\hline $\begin{array}{l}\text { Quadro } 1 \\
\text { Dados sociodemogr }\end{array}$ & & \\
\hline & Características & \\
\hline & $\mathrm{NU}(\mathrm{N}=32)$ & $\mathrm{U}(\mathrm{N}=30)$ \\
\hline Sexo & & \\
\hline Masculino & $16(50,0 \%)$ & $15(50 \%)$ \\
\hline Feminino & $16(50,0 \%)$ & $15(50 \%)$ \\
\hline Faixa etária & & \\
\hline $16-19$ & $16(50,0 \%)$ & $11(36,7 \%)$ \\
\hline $20-24$ & $16(50,0 \%)$ & $19(63,3 \%)$ \\
\hline Estado civil & & \\
\hline Solteiro & $26(81,3 \%)$ & $21(70 \%)$ \\
\hline Casado & $2(6,3 \%)$ & $3(10 \%)$ \\
\hline Separado & $04(12,4 \%)$ & $6(20 \%)$ \\
\hline Com quem vive & & \\
\hline Com a família & $27(84,4 \%)$ & $24(80 \%)$ \\
\hline Outros & $5(15,6 \%)$ & $5(16,7 \%)$ \\
\hline Sozinho(a) & & $1(3,3 \%)$ \\
\hline Grau de escolaridac & & \\
\hline 1 o grau incompleto & $8(25,0 \%)$ & $13(43,3 \%)$ \\
\hline 2 o grau incompleto & $8(25,0 \%)$ & $7(23,3 \%)$ \\
\hline 2o grau completo & $14(43,8 \%)$ & $9(30 \%)$ \\
\hline 3o grau incompleto & $2(6,2 \%)$ & $1(3,4 \%)$ \\
\hline Estudo (atualmente & & \\
\hline Estuda & $17(53,1 \%)$ & $7(23,3 \%)$ \\
\hline Não estuda & $15(46,9 \%)$ & $23(76,7 \%)$ \\
\hline Trabalho & & \\
\hline Trabalha1 & $13(40,6 \%)$ & $6(20 \%)$ \\
\hline Não trabalha² & $19(59,4 \%)$ & $24(80 \%)$ \\
\hline
\end{tabular}

1 Incluídos os entrevistados que desempenham atividade remunerada regularmente registrada.

2 Incluídos os entrevistados desempregados ou que desempenham atividades remuneradas não-registradas, ou seja, consideradas "bicos".

carrinho de areia, dá 5 pedra pro outro e o outro vai jogar o cara no rio e daí já era. (LE21MU)

(Define-se como bocada, o local de venda de drogas psicotrópicas ilícitas, seja dentro da favela ou em seus arredores).

Considerando-se primeiramente a escolaridade, cerca de 17 não-usuários não completaram o 2 o grau, dos quais 6 pararam de estudar, revelando uma taxa de abandono dos estudos equivalente a $35,3 \%$. Essa taxa chega a $70 \%$ na população usuária, em que a grande maioria ainda não completou o 2 o grau $(\mathrm{N}=20)$ e dos quais 14 não estudam atualmente por falta de interesse. Os motivos subjacentes ao abandono são distintos nos dois grupos. Os não-usuários desistem do estudo em função da prioridade dada ao trabalho, às tarefas domésticas ou a outras dificuldades inerentes à condição financeira desfavorável; os usuários o fazem em decorrência do consumo da droga, que prejudica sua capacidade de concentração, aprendizado, interesse e sobretudo a disposição física para a realização da atividade escolar, conforme já descrito por Nappo et al. (1996).

Tinha que trabalhar e deixei o estudo por causa do trabalho, porque eu tinha que ajudar os meus pais na roça, então ficava difícil de trabalhar e estudar ao mesmo tempo. (G24FNU)

Achava um saco estudar, não gostava de jeito nenhum... Não gostava, ia uma vez por mês na escola, aí eu parava de estudar, não ia mais todo dia. Eu saía de casa pra ir pra escola, mas não ia pra escola, ia andar, ia pra pracinha fumar... (E19FU)

Ainda considerando-se a população usuária, a grande maioria não dispõe de vínculo empregatício fixo $(\mathrm{N}=24)$, realizando atividades remuneradas que não requerem grande esforço, responsabilidade ou atenção ("os bicos”), cujo desempenho é destinado principalmente à obtenção da droga. Em sua maioria são atividades ligadas diretamente ao tráfico 
(ex.: "aviãozinho" - definido como um pequeno traficante que faz a entrega da droga, do seu ponto de venda ao consumidor. É um agente intermediário no tráfico e comércio de drogas, que busca na função um meio de adquirir a droga para seu próprio consumo), porém, não é rara a realização de atividades comuns como o artesanato e vendas em geral. Os "bicos" são atividades também desempenhadas por não-usuários, em menor freqüência e sem ligação com o tráfico (ex.: entrega de panfletos, cuidar de carros, venda de produtos naturais, etc.), tendo como meta o auxílio na complementação da renda familiar.

... vendendo produtos naturais a base de mel para gripes, tosses... (J23MNU)

Tô fazendo uns biquinhos aí, o que dá pra fazer eu faço, tipo: "Vem aqui que eu tenho umas drogas pra vender", eu vendo. Levo uma quota ali, levo outra quota lá... (F20FU)

Assim, corroborando com os dados encontrados por outros autores, observa-se que o usuário pesado de drogas cada vez mais foca seus recursos e energias na aquisição e consumo da droga, afastando-se do desempenho de compromissos como as atividades escolares e trabalho (Nappo et al., 1996; Miller, 1998).

\section{Fatores protetores}

Ambos os grupos entrevistados foram questionados a respeito dos possíveis fatores protetores (Hanson, 2002) que impediriam algumas pessoas de experimentarem drogas, mesmo quando imersas em local sujeito às regras impostas pelo tráfico, como a favela e seus arredores. Coincidentemente, tanto os fatores citados quanto a sua ordem de importância foram semelhantes entre os grupos e são apresentados no quadro 2 .

\subsection{Família}

Neste trabalho, o termo "família" foi definido como a união de pessoas, seja por laços de parentesco, pelo sangue ou por aliança, que vivessem na mesma casa. Em geral, a família dos entrevistados era constituída pelo pai, a mãe e os filhos, embora tenha sido freqüente o relato de entrevistados que vivessem e tivessem contato com apenas um dos progenitores, no caso, a mãe (NU=09; $\mathrm{U}=16)$. Outros ainda relataram a separação dos pais, permanecendo com a mãe e passando a conviver com uma pessoa de fora, o padrasto, que a partir de certo momen- to passa a ser considerado sendo do núcleo, ou seja, da família.

A família foi o fator protetor mais freqüentemente citado pelos entrevistados de ambos os grupos, adquirindo importância na estruturação do ser, fornecendo, segundo os próprios entrevistados, elementos essenciais como apoio, carinho e proteção. A família, como fator protetor, foi mencionada por 25 dos 32 não-usuários entrevistados, apresentando-se, neste grupo, como base fundamental da educação na infância e adolescência e como parâmetro de controle das atitudes e companhias dos filhos.

... eu acho que se minha família fosse assim toda desestruturada eu acho que seria fácil eu me envolver no mundo de drogas, mas como não é,é por isso que eu não estou neste meio. (M16MNU)

Acho que os pais devem estar bem cientes com quem você está andando, até uma certa idade. Que nem, hoje eu posso andar com quem for porque eu tenho minha opinião formada. Quando você tem até uns 12 anos ou mais, seus pais têm que ficar em cima. (M20MNU)

... os pais que geralmente trabalham, os filhos sempre têm algum problema, infelizmente, né, porque a família está muito desestruturada hoje em dia. E isso é o que principalmente contribui. (S22FNU)

Dos 30 usuários entrevistados, 21 citam a família como fator protetor, deixando claro que o esteio familiar é necessário não apenas na imposição de regras, mas também no amparo diante de toda e qualquer dificuldade, permitindo-nos supor, em associação com outros dados do questionário, que a maioria destes entrevistados era originada de famílias mal-estruturadas, caracterizadas como negligentes quanto aos aspectos de educação e atenção aos filhos.

Quando você tem uma família que você tem tudo, que tem carinho, amor, conversa, diálogo, tem uma pessoa que você pode se abrir, entendeu, acho que é diferente. (F19FU)

Eu acho que a estrutura familiar é principal, a educação... Porque ser pobre não quer dizer ser mal-educado e tal. Tem muita família humilde que educa bem os filhos. (C24MU)

Família ajuda, claro, porque a família é a base de tudo! (L21MU)

Em síntese, os dados acima são corroborados por outros estudos (Catalano et al., 1992; Hoffman, 1993; Newcomb, 1995; Piko, 2000; Blum et al., 2003), que mostram que uma família desestruturada, caracterizada pela falta 
de diálogo e interação afetiva entre seus membros, baixo envolvimento dos filhos nas atividades familiares e pouco controle dos pais sobre suas amizades e atividades desenvolvidas, funciona como influência negativa, facilitando o consumo de drogas por adolescentes.

\subsection{Informação}

A informação foi considerada uma coleção de conhecimentos amplos e fundamentados acerca das conseqüências negativas, advindas do consumo abusivo de drogas, sobre os usuários e seus relacionamentos. A mídia, escola, religião e família foram considerados os principais meios de veiculação dessa informação, que tem como intuito a instrução e o direcionamento dos jovens.

A disponibilidade dessa informação foi considerada o terceiro fator de proteção mais importante, tanto por não-usuários $(\mathrm{N}=19)$ quanto por usuários $(\mathrm{N}=14)$, que enfatizaram-na como fundamental em termos da educação sobre as drogas e seus riscos. A informação para crianças, acerca dos efeitos adversos e imediatos da droga, já foi sugerida como importante elemento na elaboração de programas de prevenção pelo NIDA (1997), sendo citada como fundamental por outros autores (Lerner, 1990).

No entanto, no grupo de não-usuários, o tipo de informação mais citada $(\mathrm{N}=13)$ como fator protetor foi aquela gerada pela experiência pessoal, ou seja, pela observação dos acontecimentos correntes num local onde a droga permeia. A observação da morte de jovens decorrente do vício ou por envolvimento com a criminalidade da região ("acerto de contas"), além de situações onde o dependente passou a vender pertences familiares, prostituir-se ou cometer crimes para a aquisição da droga são citadas como atitudes indignas por não-usuários, as quais justificariam o seu desinteresse pela droga.

Eu acho que é mais por não querer ser bandido, não ser ladrão, não querer se envolver numa aventura que não tem volta. (B17MNU)

... eu nunca quis experimentar pra não usar sempre, por medo de gostar. Tipo, muitas meninas se prostituem, pessoas roubam, tiram coisas de dentro de casa, sofrem porque eu acho que deve dar um sentimento muito ruim dentro de você. Você perde o emprego, perde a família... (C23FNU)

... o mais inteligente é aquele que aprende com os erros dos outros, então, eu acredito que

\begin{tabular}{lcr}
\hline Quadro 2 & \\
Freqüência dos fatores protetores citados pelos entrevistados \\
\hline Fatores protetores & $\mathrm{NU}=\mathbf{3 2}$ & $\mathbf{U}=\mathbf{3 0}$ \\
Família & $25(78,1 \%)$ & $21(70,0 \%)$ \\
Religiosidade & $24(75,0 \%)$ & $15(50,0 \%)$ \\
Informação & $19(59,4 \%)$ & $14(46,7 \%)$ \\
Perspectivas de futuro & $16(50,0 \%)$ & $14(46,7 \%)$ \\
Personalidade/consciência & $11(34,4 \%)$ & $14(46,7 \%)$ \\
Amor próprio & $5(15,6 \%)$ & $4(13,3 \%)$ \\
Medo & $8(25,0 \%)$ & $7(23,3 \%)$ \\
Amizades não-usuárias & $2(6,3 \%)$ & $1(3,3 \%)$ \\
\hline
\end{tabular}

com os erros dos outros a gente pode mudar o nosso caráter e escolher o que fazer. (F23MNU)

Da mesma forma, os usuários, vítimas constantes das conseqüências negativas oriundas da dependência, acreditam que o relato de sua experiência pode atuar como gerador do medo em adolescentes não-usuários, afastando-os do consumo de drogas. Dos 14 usuários que citaram a informação relevante como fator protetor, $50 \%(\mathrm{~N}=7)$ fizeram essa associação direta entre a informação e o medo por ela gerado. Assim, esses dados favoreceriam o papel do modelo preventivo baseado no amedrontamento, contradizendo assim, a observação desse como "modelo ultrapassado" (Carlini et al., 1990). Em contrapartida, conforme o modelo preventivo de princípio moral sugerido por Carlini et al. (1990), os demais usuários atribuíram à informação um papel de "construtora da personalidade", sendo essa informação geralmente oriunda dos princípios morais pregados pela família e religião.

Se a pessoa souber por que que não deve, o que aquilo faz, ela não vai usar. A informação traz o medo. Você parar e falar assim "Não, isso daqui faz isso, faz aquilo" ai traz o medo. A pessoa vai ficar insegura e não vai querer. (B18FU)

Sem contar as brigas dos meus pais, meu pai foi uma pessoa que sempre trouxe coisas boas pra gente. Foi muito presente. Tudo que ele falava pra gente, a gente sempre acreditou. Tudo que ele falou que era legal, era legal mesmo. A gente sempre acreditou muito nos nossos pais, tanto eu quanto as minhas outras duas irmãs. (D22FNU)

Observa-se que cerca de $32,0 \%(\mathrm{~N}=6)$ dos não-usuários e $21,4 \%(\mathrm{~N}=3)$ dos usuários, que citaram a informação como fator protetor relevante, destacaram o importante papel da religião como sua fonte geradora.

A religião mostra que a gente não deve usar, isso não é de Deus. As pessoas que é cristão, as- 
sim, sabem principalmente pela Igreja que não podem usar, que é pecado, né. (B17MNU)

Acho que até mesmo porque pelo centro espírita a gente estuda as conseqüências que a droga pode trazer não só para o seu organismo, mas pro seu espírito. Acho que isso também, faz com que eu fique meio "assim" pra não me fazer mal. (L18FNU).

\subsection{Religiosidade}

Para a melhor compreensão dos resultados acerca da importância da religiosidade como fator protetor, faz-se necessária a conceituação dos termos religiosidade e espiritualidade. Conforme proposto por Sullivan (1993), a espiritualidade é uma característica única e individual que pode ou não incluir a crença em um "deus", sendo responsável pela ligação do "eu" com o universo e com os outros. Engloba a necessidade de busca do bem-estar e crescimento, além da percepção do significado do mundo e daquilo que realmente valeria à pena. A religiosidade, segundo Miller (1998), consistiria na crença e prática dos fundamentos propostos por uma religião.

A religiosidade foi o segundo fator protetor mais citado pelos entrevistados. Ela se apresentou como importante meio de prevenção segundo a ótica de 24 não-usuários e de 15 usuários. Baseando-se nas definições propostas por Bucher (1988) de prevenção primária, secundária e terciária, identificou-se o seguinte quadro quanto à religiosidade: os não-usuários atribuem-lhe o importante papel como fator preventivo primário, ou seja, a religiosidade impede-os de iniciar o consumo de drogas. Em contrapartida, os usuários atribuem à religiosidade a importância como fator preventivo secundário ou terciário, ajudando-os no abandono do consumo ou até na sua redução drástica, expondo-os a um menor prejuízo. Em ambos os grupos, apesar de cumprir funções diferentes, a religiosidade surge como um poderoso fator protetor, assim, mostrando sua importância quando se trata do consumo de drogas.

Por intermédio dos fundamentos pregados, a religiosidade auxiliaria na construção da personalidade do indivíduo, incutindo-lhe valores morais que têm por fim o respeito e a preservação da vida, como já descrito por Miller (2000).

O importante é que a religião ajuda a pessoa a desenvolver seu caráter, aprender coisas certas aí ela vai saber escolher melhor. (F23MNU)
... eu acho que toda a religião mostra o caminho, um padrão, "não às drogas", "não à bebida" essas coisas... Toda religião mostra esse caminho de não se prejudicar, entendeu. E eu acho que a droga seria uma forma de prejudicar, então a igreja é contra. (R17MNU)

Acho que a religião mostra um pouco sobre o que está acontecendo, e eles vêem que não é certo usar, que é errado. Muda a cabeça da pessoa quando começa a ir na igreja. Muda. (A20FU)

Além disso, a religiosidade gera a crença na existência de um Ser Superior, cujas leis visariam sempre ao bem-estar do indivíduo. Ela é também considerada uma "fonte de forças" independentemente da religião professada, sugerindo cuidados físicos e mentais, associados ao não-uso de drogas.

Creio que a religião é uma influência muito grande é ter Jesus no coração pra fazer a vontade Dele. Acho que pra mim, sinceramente, foi o que mais me ajudou, o que mais me ajuda realmente a estar vencendo isso porque tá na cara, se eu não vigiar, se eu não pedir força pra Ele, amanhã ou depois eu posso ter uma fraqueza.... (J23MNU)

Se você tem fé, se você acredita em você, acredita em Deus, você não vai usar. Sei lá, vai da pessoa, vai da fé de cada um... (F18FU)

2.3.1 a religião do entrevistado - Considerando-se o entrevistado, observa-se que 96,9\% dos não-usuários $(\mathrm{N}=31)$ acreditam em alguma religião e cerca de $81 \%$ dessa amostra praticam-na $(\mathrm{N}=26)$ (Quadro 3).

A prática, aos não-usuários, surge muitas vezes por vontade própria como um meio de se alcançar a realização espiritual, a resolução de problemas pessoais e também como engajamento nas atividades desempenhadas pela instituição religiosa freqüentada (cultos, grupo de jovens, atividades sociais voluntárias, entre outras), conforme já descrito por Graunbaun et al. (2000). Ainda de acordo com esse autor, a freqüência regular à instituição religiosa diminuiria a chance do consumo de drogas ilícitas como a maconha e cocaína por jovens.

Eu vivi a maior parte da minha vida, dos 15 aos 17 na Igreja. Fiz trabalho paroquial, grupo de jovens, cantava, fazia teatro, catequese... Nossa, eu tinha um pedacinho da igreja pra mim, um pouquinho dona dali, entendeu? (A21FNU)

... eu acho que eu tava precisando de alguma coisa a mais, que me contentasse, além do meu namorado, da minha família, apesar do meu pai ter melhorado bastante... Eu tava sentindo falta, então eu falei é a igreja, eu gosto muito. Na igreja eu participava do trabalho de missões, a gente 
Quadro 3

A crença, prática e tipo de religiões professadas pelos entrevistados

\begin{tabular}{|c|c|c|}
\hline \multicolumn{3}{|c|}{ Entrevistados } \\
\hline & $\mathrm{NU}=32$ & $\mathrm{U}=\mathbf{3 0}$ \\
\hline \multicolumn{3}{|l|}{ Religião } \\
\hline Com religião & $31(96,9 \%)$ & $10(33,3 \%)$ \\
\hline Sem religião & $1(3,1 \%)$ & $20(66,7 \%)$ \\
\hline \multicolumn{3}{|l|}{ Prática 1} \\
\hline Praticante & $26(81,3 \%)$ & $4(13,3 \%)$ \\
\hline Não-praticante & $5(18,7 \%)$ & $6(18,8 \%)$ \\
\hline \multicolumn{3}{|l|}{ Religiões aceitas 2} \\
\hline Católica & $12(38,7 \%)$ & $5(50,0 \%)$ \\
\hline Evangélicas/Protestantes & $10(32,3 \%)$ & $1(10,0 \%)$ \\
\hline Espírita & $3(9,6 \%)$ & $2(20,0 \%)$ \\
\hline Umbanda & $2(6,5 \%)$ & 0 \\
\hline Daime & 0 & $1(10,0 \%)$ \\
\hline Sincrético 4 & $4(12,9 \%)$ & $1(10,0 \%)$ \\
\hline \multicolumn{3}{|l|}{ Religiões praticadas 3} \\
\hline Católica & $9(75,0 \%)$ & $2(40,0 \%)$ \\
\hline Evangélicas/Protestantes & $9(90 \%)$ & 0 \\
\hline Espírita & $3(100 \%)$ & $1(50 \%)$ \\
\hline Umbanda & $2(100 \%)$ & 0 \\
\hline Daime & 0 & $1(100 \%)$ \\
\hline Sincrético 4 & $3(75 \%)$ & 0 \\
\hline
\end{tabular}

1 As freqüências da prática da religião são relativas ao número total da amostra.

2 As freqüências das religiões aceitas são relativas ao total de entrevistados COM RELIGIÃO, dentro de cada um dos grupos.

3 As freqüências das religiões praticadas são relativas às religiões correspondentes no item RELIGIÕES ACEITAS.

4 Considerou-se sincrético o entrevistado que disse acreditar nos princípios e postulados de duas ou mais religiões, criando a

"sua própria religião", oriunda de uma mescla de conceitos preestabelecidos.

ia na favela, buscava as crianças pra ir lá ouvir a palavra... (S22FNU)

Os não-usuários que não praticam a religião $(\mathrm{N}=5)$ já o fizeram em alguma época da vida, atribuindo a não-prática atual à falta de tempo, dedicando-se integralmente ao estudo e trabalho $(\mathrm{N}=4)$ ou, até mesmo, pela discordância com respeito a alguns aspectos dogmáticos da religião $(\mathrm{N}=1)$.

Freqüentava direto, aí comecei a estudar à noite, daí eu parei de ir. Hoje eu quase não tenho tempo, trabalho à noite e estudo de manhã. Sábado e domingo eu tenho que fazer as coisas, eu tenho que fazer alguns trabalhos e daí não sobra tempo. Eu tenho convicção que eu ainda vou voltar pra igreja, então eu quero voltar sabendo que eu não fiz, entre aspas, nada de errado. (F20MNU)

Freqüentava sempre, aí comecei a trabalhar aí sai do grupo, aí acabei não entrando de novo, mas já freqüentei muito. (N18FNU)

Em contraposição, 33,3\% dos usuários $(\mathrm{N}=10)$ acreditam em alguma religião e apenas $13,3 \%$ dessa amostra $(\mathrm{N}=4)$ praticam-na (Quadro 3), justificando a prática na procura de estí- mulos que lhes proporcionassem o desinteresse e conseqüente abandono da dependência, corroborando com os dados já apresentados por Carter (1998), Pullen (1999) e Arnold et al. (2002).

Hoje eu sou espírita, minha irmã também é espírita então o Espiritismo ele prega muito a sanidade mental por isso ajuda afastar das drogas. (C24MU)

Ultimamente eu tô tomando Daime. Tô gostando muito, tô me encontrando espiritualmente com isso, parei um pouco de usar droga inclusive por causa do Daime. Depois do Daime eu parei, dei um tempo muito forte assim com cigarro e com álcool. (B20MU)

Dos usuários não-praticantes $(\mathrm{N}=6)$, três nunca exerceram nenhum tipo de atividade religiosa na vida, enquanto que os demais atribuíram a não-prática atual ao desinteresse, descrença, preguiça e até mesmo pela não-adaptação às práticas realizadas no grupo religioso.

Os depoimentos a seguir ilustram a preguiça, descrença e o desinteresse dos usuários pela prática religiosa. 
Vixe, tinha tanto domingo que eu chegava muito louco e minha mãe queria ir na missa e eu ia na missa loucão, sentava no fundo e ficava dormindo. ( M24MU)

... depois da catequese tinha que ir pra missa, putz, eu odiava, queria ir embora. Era no domingo tinha que acordar cedo nossa, eu odiava a catequese. (M19MU)

Há muito tempo atrás freqüentei, mas também não gostava não! Tinha umas gritaria e eu não entrava na bagunça. (F18FU)

... não acreditava muito na palavra deles. (R18MU)

A religião católica foi a mais citada pelos entrevistados de ambos os grupos, porém, foi a menos praticada (Quadro 3). Além disso, entre os não-usuários, as religiões evangélicas/protestantes despontam como uma das mais citadas e praticadas, corroborando com os dados propostos por Patock-Peckham (1998). Esse autor observou que apesar de adolescentes religiosos serem menos propensos ao consumo e dependência de álcool, aqueles que praticavam religiões protestantes faziam uso ainda menor quando comparado a outras religiões.

Em contraposição, a grande maioria dos usuários não tem ou não acredita na religião, idéia já exposta por Miller (1998), que sugeriu que a droga, para os usuários e dependentes de substâncias psicotrópicas, ocuparia a posição do Ser Superior pertencente a Deus para os religiosos.

2.3.2 religião na família do entrevistado Levando-se em consideração os não-usuários, dos 25 entrevistados que citaram a família como fator protetor, 19 deles ressaltaram também a importância da religião $(76 \%)$, mostrando que se tratariam de conceitos inter-relacionados. Essa possibilidade levou à investigação da freqüência da crença e prática da religião na família dos entrevistados, com o intuito de verificar qual a "real" importância da religião sobre a vida dessas pessoas.

De acordo com os dados apresentados no quadro 4, a maioria dos familiares de nãousuários e usuários acredita numa religião $(\mathrm{NU}=29 ; \mathrm{U}=25)$, onde a religião católica é a mais freqüentemente citada $(\mathrm{NU}=14 ; \mathrm{U}=19)$.

Porém, a prática da religião professada é um fator de diferenciação entre os grupos, ou seja, enquanto cerca de $73,3 \%$ dos familiares religiosos de não-usuários praticam a religião escolhida ( $\mathrm{N}=22)$, apenas $33,3 \%$ dos familiares de usuários o fazem $(\mathrm{N}=10)$. A religião católi$\mathrm{ca}$, embora mais freqüente, parece ser a religião menos praticada em ambos os grupos, ao contrário das religiões evangélicas/protestantes que despontaram entre as mais acreditadas e praticadas, dado que corrobora com os resultados anteriores acerca da importância da religiosidade entre os próprios entrevistados. Afirmações mais conclusivas a respeito da prática nas demais religiões são difíceis de serem estabelecidas, uma vez que foram pouco citadas pelos entrevistados.

Segundo o depoimento de não-usuários, a religião na família é importante em sua estruturação e como influência a ser seguida, fornecendo uma educação que afastaria o sujeito de comportamentos de risco que culminariam no uso da droga.

Eu acho que se a família tem uma religião desde pequeno, que cria aquela criança, não usa, independente da religião. (C23FNU)

Eu rezo. A gente pega a Bíblia e lê, esse tipo de coisa. Fé em Deus, mas eu estou pretendendo entrar para uma igreja. A minha namorada começou recentemente e eu estou querendo entrar também, mas não sei em qual. (M20MNU)

Todas nós, as 3 irmãs foram educadas aprendendo a rezar. A gente sabe todas as orações e rezamos todos os dias e ele (pai) sempre falou pra gente rezar diante dos problemas. (D22FNU)

\subsection{Perspectivas de futuro}

Outro fator protetor muito citado diz respeito às perspectivas de futuro do adolescente em situação de risco, ou seja, o estabelecimento de uma meta ou plano de vida e a devoção à sua realização, por mais difícil ou impossível que pudesse parecer. $\mathrm{O}$ estabelecimento de uma perspectiva, como forma de realização pessoal e conseqüente bem-estar, estaria intimamente relacionado ao despertar da espiritualidade do indivíduo, conceito já exposto no item Religiosidade.

A influência positiva da perspectiva foi abordada por não-usuários $(\mathrm{N}=16)$ como importante contribuinte no sonho de se "afastar da favela", "formar uma família unida", "fazer faculdade", "ser alguém na vida", permitindo, assim, observação de focos bem definidos para o futuro e conseqüente afastamento do indivíduo do interesse pela droga e suas complicações, visto que têm claro o quanto a droga poderia atrapalhá-los na conquista de metas e no futuro que almejam.

Você tem que ter alguma coisa pra você lutar, todo mundo tem... (C17FNU) 
Quadro 4

A crença, prática e tipo de religiões professadas pelos familiares dos entrevistados

\begin{tabular}{lrr}
\hline & Familiares & \\
\hline Religião & NU=301 & U=30 \\
Com religião & & \\
Sem religião & $29(90,6 \%)$ & $25(83,3 \%)$ \\
Prática 3 $_{\text {Praticante }}$ & $1(3,1 \%)$ & $5(16,7 \%)$ \\
Não-praticante & $22(73,3 \%)$ & $10(33,3 \%)$ \\
Religiões aceitas 2,4 & $7(23,3 \%)$ & $15(50,0 \%)$ \\
Católica & & $19(76,0 \%)$ \\
Evangélicas/Protestantes & $14(48,3 \%)$ & $5(20,0 \%)$ \\
Espírita & $9(31,0 \%)$ & $1(4,0 \%)$ \\
Umbanda & $4(13,8 \%)$ & 0 \\
Religiões praticadas 5 & $2(6,9 \%)$ & $7(36,8 \%)$ \\
Católica & & $3(60,0 \%)$ \\
Evangélicas/Protestantes & $8(57,1 \%)$ & 0 \\
Espírita & $8(88,9 \%)$ & 0 \\
Umbanda & $4(100 \%)$ & \\
\hline
\end{tabular}

1 Não pudemos considerar os dados de duas entrevistadas não-usuárias pelo fato de terem sido abandonadas na infância e, desde então, passaram a morar em instituições que abrigam órfãos e abandonados. Assim sendo, as entrevistadas não moram com familiares e não possuem conhecimento a respeito da crença e prática religiosa na família de origem.

2 A religião aceita pela família, segundo o entrevistado, consistiu na religião de maior relevância no núcleo familiar.

3 As freqüências da prática da religião são relativas ao número total da amostra.

4 As freqüências das religiões aceitas são relativas ao total de famílias COM RELIGIÃO, em cada um dos grupos;

5 As freqüências das religiões praticadas são relativas às religiões correspondentes no item RELIGIÕES ACEITAS.

Então, quem quer um futuro bom não vai entrar na droga, vai pensar adiante e não vai querer entrar. (C23FNU)

... eu quero mostrar para eles que eu quero conquistar as minhas coisas em vez de acabar com a minha vida. (M17FNU)

Dentre os usuários, fica clara a despreocupação com o futuro que tinham ao entrar nas drogas, visto que agora identificam a perspectiva de futuro como um fator protetor $(\mathrm{N}=14)$, admirando os colegas que buscam algo de bom para o futuro.

Acho que quem não usa busca ter uma vida melhor, porque ele sabe que com droga não vai dar. (A24FU)

Acho que o pobre não quer saber de drogas, principalmente pelas condições que ele vive, acho que ele quer uma coisa melhor, um futuro melhor... Ele sabe que usando droga não vai ter um futuro melhor. Ele quer lutar pra ser melhor, conseguir ter alguma coisa um dia... (E19FU)

Assim, observamos que a espiritualidade parece despontar de formas diferentes na vida de usuários e não-usuários. Enquanto que a espiritualidade é clara na vida de não-usuários, essa qualidade, não desperta em usuários em período anterior ao consumo, adquire relevância como forma de recuperação da dependência. A importância da espiritualidade no tratamento e recuperação de dependentes de substâncias psicotrópicas já foi relatada por Carter (1998) e Green et al. (1998).

\section{Conclusões}

O consumo e a dependência de substâncias psicotrópicas, por adolescentes, podem ser evitados mesmo em ambientes caracterizados pela abundância de fatores de risco, como observado em favelas e arredores, onde o tráfico "dita as regras" de acordo com as suas necessidades. Essa prevenção pode ser facilitada pela presença de fatores protetores na vida do indivíduo, ou seja, aspectos e conceitos de grande valia que parecem influenciar o não-uso de drogas. A estrutura familiar, a religiosidade, a disponibilidade de informações acerca da dependência e suas conseqüências e o estabelecimento de perspectivas de futuro foram relatadas como os fatores protetores mais importantes. Porém, chama especial atenção o papel desempenhado 
pela espiritualidade e religiosidade do entrevistado.

A espiritualidade apresentou-se desperta em todos os entrevistados não-usuários que, através do desinteresse pelo consumo de drogas e suas implicações, mostraram uma preocupação quanto à manutenção de seu bem-estar e auto-preservação, atribuída principalmente ao fato de estabelecerem planos de futuro em sua vida. O despertar dessa espiritualidade pareceu-nos intimamente associada com a religiosidade, já que a maior parte dos entrevistados desse grupo acreditava e praticava uma determinada religião. Em contrapartida, a maioria dos usuários não apresentou indícios de religiosidade e nem sequer a crença em uma religião, fatos que poderiam justificar a ausência de valorização da vida, decorrentes da pouca espiritualidade nesse grupo. Curiosamente, o mesmo grupo citou a religiosidade como importante fator protetor.

A religiosidade, além de se tratar de um aspecto muito relevante para os entrevistados, parece ocupar importante papel na estruturação da família, responsável pela humanização do indivíduo, auxiliando-o na construção de sua personalidade. Também aparece como importante fonte divulgadora de informações quanto aos aspectos negativos do uso de drogas. Assim, a religiosidade teria uma função ampla, permeando entre os demais fatores protetores citados pela amostra, como ocorre para a família, informação e perspectivas de futuro.

Em vista desses resultados, faz-se necessária a realização de outros estudos que comprovem a importância da religiosidade como fator protetor do uso de drogas, considerando a possibilidade de sua introdução em modelos de prevenção.

\section{Agradecimento}

À Fapesp pela bolsa de mestrado concedida à primeira autora (processo 01/11702-9) e pelo Auxílio Pesquisa concedido à orientadora para o projeto (02/06929-7).

\section{Referências bibliográficas}

Arnold RM, Avants SK, Margolin A \& Marcotte D 2002. Patient attitudes concerning the inclusion of spirituality into addiction treatment. Journal of Substance Abuse Treatment 23:319-326.

Baus J, Kupek E \& Pires M 2002. Prevalência e fatores de risco relacionados ao uso de drogas entre escolares. Revista de Saúde Pública 36(1):40-6.

Biernarcki P \& Waldorf D 1981. Snowball samplingproblems and techniques of chain referral sampling. Sociological Methods and Research 10:141-163.

Blum RW et al. 2003. Adolescent health in the Caribbean: risk and protective factors. American Journal of Public Health 93(3):456-460.

Bucher R 1988. A abordagem preventiva, pp. 55-67. In R Bucher. As drogas e a vida: uma abordagem biopsicossocial. EPU, São Paulo. 
Carlini EA, Carlini-Cotrim BHRS \& Silva-Filho AR 1990. Sugestões para programas de prevenção ao abuso de drogas no Brasil. CEBRID, São Paulo.

Carr MB \& Vandiver TA 2001. Risk and protective factors among youth offenders. Adolescence 36(143):409426.

Carter TM 1998. The effects of spiritual practices on recovery from substance abuse. Journal of Psychiatric and Mental Health Nursing 5:409-413.

Catalano RF et al. 1992. Ethnic differences in family factors related to early drug initiation. Journal of Studies on Alcohol 53(3):208-217.

Chaturvedi HK, Phukan RK \& Mahanta J 2003. The association of selected sociodemographic factors and differences in patterns of substance use: a pilot study in selected areas of Northeast India. Substance Use \& Misuse 38(9):1305-1322.

Creswell JW 1998. Qualitative inquiry and research design: choosing among five traditions. Sage Publications, USA.

De Micheli D \& Formigoni MLS 2001. As razões para o primeiro uso de drogas e as circunstâncias familiares prevêem os padrões de uso futuro? Jornal Brasileiro de Dependência Química 2(1):20-30.

Dupont RL 1987. Prevention of adolescent chemical dependency. Pediatric Clinics of North America 34(2):495-505.

Francis LJ 1997. The impact of personality and religion on attitude towards substance use among 13-15 year olds. Drug and Alcohol Dependence 44:95-103.

Galduróz JCF, Notto AR \& Carlini EA 1998. IV Levantamento sobre o uso de drogas entre estudantes de 10 e $2 \underline{o}$ graus em 10 capitais brasileiras. CEBRID, Universidade Federal de São Paulo.

Graunbaum JA, Tortolero S, Weller N \& Gingiss P 2000. Cultural, social, and intrapersonal factors associated with substance use among alternative high school students. Addictive Behaviors 25(1):154-151.

Green LL, Fullilove MT \& Fullilove RE 1998. Stories of spiritual awakening: the nature of spirituality in recovery. Journal of Substance Abuse Treatment 15(4): 325-331.

Hanson GR 2002. New vistas in Drug Abuse Prevention. NIDA NOTES 16(6):3-7.

Hoffmann JP 1993. Exploring the direct and indirect family effects on adolescent drug use. The Journal of Drug Issues 23(3):535-557.

Huesca RS, Cruz VMG, Encinas RO \& Pantoja GL 2002. Detección temprana de factores de riesgo para el consumo de substancias ilícitas. Salud Mental 25(3):1-11.

Kandel D \& Logan JA 1984. Patterns of drug use from adolescence to young adulthood. I. Period of risk for initiation, continued use and discontinuation. American Journal of Public Health 74(7):660-666.

Lerner R 1990. Atribuiciones de razones a las conductas de consumo y no consumo de drogas. Psicoativa $4(7): 21-46$.
Miller L, Davies M \& Greenwald S 2000. Religiosity and substance use and abuse among adolescents in the National Comorbidity Survey. Journal of the American Academy of Child and Adolescent Psychiatry 39(9):1190-1197.

Miller WR 1998. Researching the spiritual dimensions of alcohol and other drug problems. Addiction 93(7): 979-990.

Minayo MCS 1993. O desafio do conhecimento - pesquisa qualitativa em saúde. Hucitec, São Paulo.

Newcomb MD 1995. Identifying high-risk youth: prevalence and patterns of adolescent drug abuse. NIDA Research Monograph 156:7-37.

Nappo SA, Galduróz JCF \& Noto AR 1996. Crack use in São Paulo. Substance Use \& Misuse 31 (5):565-579.

NIDA (National Institute on drug Abuse) 1997. Preventing drug use among children and adolescents - A research based guide. NIH Publication, Princeton.

Patock-Peckham JA, Hutchinson GT, Cheong J \& Nagoshi CT 1998. Effect of religion and religiosity on alcohol use in a college student sample. Drug and Alcohol Dependence 49:81-88.

Patton MQ 1990. Qualitative evaluation and research methods. Sage Publications, Londres.

Pentz, MA 2003 Evidence-based prevention: characteristics, impact, and future direction. Journal of Psychoactive Drugs. 35(Suppl. 1):143-152.

Piko B 2000. Perceived social support from parents and peers: which is the stronger predictor of adolescent substance use? Substance Use \& Misuse 35(4):617630.

Pullen L Modricin-Talbott MA, West WR \& Muenchen R 1999. Spiritual high vs high on spirits: is religiosity related to adolescent alcohol and drug abuse? Journal of Psychiatric and Mental Health Nursing 6:3-8.

Sanchez ZM \& Nappo SA 2002. A seqüência de drogas consumidas por usuários de crack e fatores interferentes. Revista de Saúde Pública 36(4):420-430.

Scheier LM, Newcomb MD \& Skager R 1994. Risk, protection, and vulnerability to adolescent drug use: latent-variable models of three age groups. Journal of Drug Education 24(1):49-82.

Sullivan WP 1993. It helps me to be a whole person: the role of spirituality among the mentally challenged. Psychosocial Rehabilitation Journal 16:125-134.

Taylor SJ \& Bodgan R 1998. Introduction to qualitative research methods. Ed. John Wiley \& Sons, Nova York.

WHO (World Health Organization) 1994. Qualitative research for health programmes. Division of Mental Health, Geneva.

Wills TA, Yager AM \& Sandy JM 2003. Buffering effect of religiosity for adolescent substance use. Psychology of Addictive Behaviors 17(1):24-31.

Artigo apresentado em 28/8/2003

Aprovado em 6/10/2003

Versão final apresentada em 24/11/2003 